\title{
ESTRATÉGIA PARA FIDELIZAÇÃO DO CLIENTE EM TURISMO: O CASO DE UMA OKTOBERFEST NO BRASIL
}

STRATEGY FOR CUSTOMER LOYALTY IN TOURISM: THE CASE OF THE OKTOBERFEST IN BRAZIL

ESTRATEGIAS PARA LA FIDELIZACIÓN DE CLIENTES EN TURISMO: EL CASO DE UNA OKTOBERFEST EN BRASIL

Carlos Alberto Mello Moyano

Doutor em Administração pela UFRGS imur@imur.com.uy

Jorge Francisco Bertinetti Lengler Pós-Doutor em Marketing Internacional pela University College Dublin Doutor em Administração pela UFRGS jorge@lengler.org Derli Luís Angnes Mestre em Administração pela UNISC derli.angnes@gmail.com Franco Vieira Sampaio Mestrando em Administração pela UNISC prof@francosampaio.com Data de Submissão: 25/12/2014 Data de Aprovação: 02/06/2015

RESUMO: A primeira edição da Oktoberfest de Santa Cruz do Sul/RS ocorreu no ano de 1984 e guarda as tradições dos imigrantes germânicos que se instalaram na Região Sul do Brasil. A festa chega a reunir 450 mil pessoas a cada ano, sendo a principal manifestação das tradições alemãs no Rio Grande do Sul. A importância do evento para a economia da região exige dos gestores uma procura permanente e um aprimoramento dos elementos para elevação da satisfação dos visitantes. Em virtude desta importância, o presente estudo tem como finalidade avaliar a satisfação dos visitantes da Oktoberfest de Santa Cruz do Sul, como instrumento para o desenvolvimento de estratégias de fidelização. O método utilizado apoiou-se na teoria do comportamento do consumidor e considera a adaptação do Escore Global de Satisfação do ASCI e do SCSB (FORNELL, 1992; FORNELL et al., 1996), assim como a aplicação da Matriz de Posição Competitiva (MELLO MOYANO, 
1999) e das Estratégias de Fidelização (MELLO MOYANO; LENGLER, 2011). Os resultados sugerem que uma posição competitiva positiva com clientes leais representa menos gastos em estratégias mercadológicas para manutenção e fidelização dos clientes.

Palavras-chave: Turismo. Comportamento do consumidor. Estratégia de marketing. Fidelização.

ABSTRACT: The first edition of the Oktoberfest in Santa Cruz do Sul (Brazil) took place in 1984 and since then, the festival has safeguarded the traditions of the German immigrants who settled in southern Brazil. The festival gathers 450 thousand people each year, and is the main manifestation of German traditions in the State of Rio Grande do Sul. In view of its importance to the local economy, the managers need to constantly search for ways to improve the elements, in order to increase visitors' satisfaction. Due to this importance, this study evaluates visitors' satisfaction of the Oktoberfest in Santa Cruz do Sul as a tool for developing loyalty strategies. The research method applied in this study is based on theory of consumer behavior, and considers the adapted Global Satisfaction Score ASCI and the SCSB (FORNELL,1992; FORNELL et al., 1996), as well as the application of the Competitive Position Matrix (MELLO MOYANO, 1999) and Loyalty Strategies (MELLO MOYANO; LENGLER, 2011). The results suggest that a competitive position with loyal customers represents less expenditure on marketing strategies to maintain clients.

Keywords: Tourism. Consumer behavior. Marketing strategy. Loyalty.

RESUMEN: La primera edición de la Oktoberfest en Santa Cruz do Sul (Brasil) se produjo en 1984 y mantiene las tradiciones de los inmigrantes germánicos que se establecieron en el sur de Brasil. La fiesta llega a reunir 450 mil personas cada año y es la principal manifestación de las tradiciones alemanas en Rio Grande do Sul. La importancia del evento para la economía de la región exige de los gestores una búsqueda permanente y un mejoramiento de los elementos que aumenten la satisfacción de los visitantes. En virtud de esta importancia, el presente estudio tiene como objetivo evaluar la satisfacción del visitante de la Oktoberfest de Santa Cruz do Sul, como una herramienta para el desarrollo de estrategias de fidelización. El método utilizado se basa en la teoría del comportamiento del consumidor y considera la adaptación del Score de Satisfacción Global del ASCI y del SCSB (FORNELL, 1992; FORNELL et al, 1996), así como la aplicación de la Matriz de Posición Competitiva (MELLO MOYANO, 1999) y de las Estrategias de Fidelidad (MELLO MOYANO; LENGLER, 2011). Los resultados sugieren que una posición competitiva positiva con los clientes leales representa menos gastos en estrategias de marketing para la manutención y fidelización de los clientes.

Palabras clave: Turismo. Comportamiento del consumidor. Estrategia de marketing. Fidelización.

INTRODUÇÃO

área de eventos em turismo tem proporcionado grande contribuição
para os países em termos de geração de riqueza e empregos. O setor
de eventos de turismo, especificamente o da Oktoberfest, possui uma grande raiz popular no Sul do Brasil e é responsável por gerar emprego e renda. Segundo McKercher, Mei e Tse (2006), os festivais permitem mostrar 
a cultura local e promover o fluxo de turistas. Um desses eventos no Brasil é a Oktoberfest de Santa Cruz do Sul no Rio Grande do Sul, o segundo maior festival do gênero no Brasil, que acontece desde 1984, com a finalidade de mostrar aos turistas as tradições dos imigrantes alemães no que se refere à dança, à música e à gastronomia. Os visitantes superam os 500 mil, crescendo anualmente, convertendo-se em uma grande fonte de receita para o município. O cenário atual, com uma concorrência acirrada pela captação dos turistas, exige das autoridades organizadoras o desenvolvimento de um conjunto de estratégias de marketing que sejam específicas, em função das particularidades que este setor assume. Assim, o presente estudo busca propor um método de análise e desenvolvimento de estratégias de marketing com a finalidade de aumentar a racionalidade e a eficiência do processo decisório de marketing. Como objetivos específicos deste estudo, tem-se a identificação das dimensões da qualidade para satisfação dos visitantes da Oktoberfest de Santa Cruz do Sul; a medição da avaliação do serviço recebido e a criação de uma matriz estratégica de posição competitiva, baseada na avaliação do serviço. Como resultado desta análise, propõe-se um conjunto de estratégias mercadológicas com a finalidade de fidelizar os turistas.

A sequência do artigo consistirá na apresentação do objeto do estudo, os elementos teóricos vinculados aos objetivos, do método desenvolvido e dos resultados do trabalho. Finalmente, apresenta-se um conjunto de estratégias mercadológicas fundamentadas na análise realizada que visa à retenção dos clientes.

\section{OBJETO DO ESTUDO: A OKTOBERFEST DE SANTA CRUZ DO SUL/RS}

O termo Oktoberfest significa festival de outubro em alemão e é um evento originalmente realizado na cidade de Munique no estado da Baviera desde 1810. A Oktoberfest de Munique é considerada uma das maiores festas populares do mundo. Foi o pintor e escultor alemão Ferdinand Schlatter que, ao morar em Porto Alegre/RS, fundou o grupo dos "Haberer" ou "Bávaros" no dia 4 de junho de 1903 (atualmente, um departamento cultural da Sociedade Ginástica de Porto Alegre - SOGIPA), introduzindo 
dessa forma, a festa da alegria de outubro no Rio Grande do Sul - réplica da realizada anualmente em Munique, capital da Baviera. A Oktoberfest foi realizada na SOGIPA até fins da década de 1960 e retomada a partir de 1980. Poucos anos depois, começaram a surgir edições da Oktoberfest em outras cidades gaúchas, como Santa Cruz do Sul e Igrejinha. A Oktoberfest de Santa Cruz do Sul, objeto de estudo deste trabalho, é responsável pela maior edição da Oktoberfest no Rio Grande do Sul. Teve sua primeira edição em 1984 e tem sido realizada sempre no mês de outubro com uma duração aproximada de 10 dias de festa com várias atrações aos turistas. A maior Oktoberfest brasileira ocorre na cidade de Blumenau, no estado de Santa Catarina, todas elas, fundadas por imigrantes alemães (OKTOBERFEST, 2011). Também existem versões da festa em diversos outros estados do país. A Oktoberfest no Brasil procura manter e divulgar as tradições alemãs trazidas pelos colonizadores há mais de 150 anos, considerado um evento turístico importante para o país, no qual se mostram a música, a dança e a gastronomia alemã. O número de visitantes em todas as edições realizadas no país é superior a um milhão de pessoas (OKTOBERFEST, 2013).

FUNDAMENTAÇÃO TEÓRICA

\section{LEALDADE E SATISFAÇÃO DO CONSUMIDOR DE SERVIÇOS EM}

TURISMO

A satisfação do consumidor constitui uma filosofia e um objetivo no marketing moderno, cujo consumidor é proclamado rei. Kotler $(2013 ; 2015)$ afirma que o conceito social de marketing dispõe que a tarefa da organização é determinar as necessidades, os desejos e os interesses dos mercados-alvo, de modo a satisfazer mais eficazmente e mais eficientemente o cliente que a concorrência, de maneira a preservar ou melhorar o bem-estar dos clientes e da sociedade.

Santos (2013) diz que, uma vez que produção e consumo do turismo são concomitantes, a demanda turística por um destino é resultado da expectativa de satisfação. Turistas decidem viajar a um local porque esperam satisfazer suas necessidades e desejos. 
A Satisfação do Consumidor (SC) foi definida de várias formas. Howard e Sheth (1969) a definem como "o estado cognitivo do comprador de estar sendo atendido adequada ou inadequadamente por um esforço que ele realizou". Oliver (1981) argumenta que a SC "pode ser mais bem entendida como uma avaliação da surpresa relacionada a uma experiência de compra e/ou consumo de um produto ou serviço", propondo uma integração entre teorias relacionadas ao julgamento perceptual e às respostas emocionais. Shan et. al. (2014) definem a satisfação como a avaliação da incompatibilidade entre a expectativa do consumidor e o desempenho do serviço por ele percebido. Se o desempenho que o consumidor experimentou atende ou excede às suas expectativas, o consumidor é considerado satisfeito. Segundo, Blackwell, Miniard e Engel (2013, p. 83), a satisfação "acontece quando a performance percebida confirma as expectativas dos consumidores; quando experiência e performance frustram expectativas, a insatisfação ocorre". Conforme Hunt (1977), a satisfação é "uma espécie de distância de uma experiência para avaliála. Alguém pode ter uma experiência gratificante que gere insatisfação, pois mesmo sendo gratificante, não é como deve ser. Logo, a insatisfação não é uma emoção, mas sim a avaliação de uma emoção".

Howard e Sheth (1969) afirmam que satisfação e insatisfação são polos de uma escala, em que existe um ponto intermediário de neutralidade, ao qual corresponde um estado que não é nem satisfeito, nem insatisfeito. Dessa forma, o termo satisfação será empregado como satisfação positiva ou satisfação negativa.

A satisfação é afetada por três antecedentes, conforme Anderson, Fornell e Lehmann (1994), que são: qualidade percebida, preço (valor percebido) e expectativas. Segundo Fornell et al. (1996), dois componentes auxiliam na avaliação da qualidade percebida: o grau de customização da oferta da empresa e a credibilidade dessa oferta com relação à inexistência de deficiências. valor percebido é o segundo antecedente da SC (ANDERSON; FORNELL; LEHMANN, 1994) e a qualidade relativa ao preço tem impacto direto na SC (VOSS; PARASURAMAN; GREWAL, 1998; FORNELL et al. 1996; ANDERSON, 1996). Quando o resultado não é previsível, o preço é utilizado para formar as expectativas de desempenho (GREWAL, 1995). 
Dubois (1990) define a satisfação como um estado psicológico traduzido na ausência de afastamento ou desvio entre as expectativas e a performance do produto. Conforme Evrard (1980), o consumidor, ao consumir, tem um sentimento de satisfação ou de insatisfação.

A satisfação, para Chitty et al. (2007), é uma resposta que ocorre quando os consumidores experimentam um nível prazeroso de cumprimento, a qual é relacionada com o consumo ao avaliar um produto ou serviço. Índices de satisfação são os meios para fins estratégicos, tais como: retenção de clientes e lucros.

Watanabe (2010) afirma que a satisfação é uma reação afetiva em que as necessidades, os desejos, e as expectativas do consumidor durante a compra foram atingidos ou ultrapassados. Já para Gosling, Souza e Araújo (2006), a satisfação é o estado de ser adequadamente recompensado em uma situação de compra pelos sacrifícios realizados, sendo que a avaliação feita representa que a experiência foi, pelo menos, tão boa como se esperava que fosse.

Giese e Cote (2002) apresentam uma análise na literatura sobre a definição de satisfação em que identificam três componentes comuns, entre eles: (1) a satisfação do consumidor é uma resposta (emocional ou cognitiva); (2) a resposta pertence a um foco particular (expectativas, produto, experiência de consumo) e; (3) a resposta ocorre em um determinado momento (após o consumo, após escolha, com base na experiência acumulada).

Dagger e David (2012) analisam que a relação entre satisfação e lealdade pode ser reforçada ou atenuada dependendo dos níveis de envolvimento, dos benefícios percebidos de relacionamento e dos custos de mudança. Já a satisfação no consumo envolve a avaliação da satisfação com os eventos durante o processo de consumo (tempo de espera, conforto, concessões, etc.) e resultados do consumo (eficiência, eficácia, riscos menores, status, sucesso, autoestima) (RIBEIRO; HANNA; MONTEIRO, 2006).

Alguns autores sugerem que a medida da satisfação seja feita por meio de medições objetivas, por meio do monitoramento de reclamações, do retorno para uma nova compra, ou da fidelidade à marca (BLOEMER; POLESZ, 1989), ou de medições subjetivas, em que se utilizam escalas de medidas abordando os atributos referentes ao produto ou ao serviço consumido (OLIVER, 1980; TSE; WILTON, 1988). 
Segundo Evrard (1993), a satisfação pode ser medida de maneiras diferentes. Numa aplicação mais simples, é vista com um continuum unidimensional entre dois polos opostos: satisfação (satisfaction) e insatisfação (dissatisfaction) (LABARBERA; MAZURSKY, 1983; CADOTTE; WOODRUFF; JENKINS, 1987). Essa característica unidimensional (continuum bipolar de satisfação/insatisfação) é bastante utilizada pela sua simplicidade.

Westbrook (1980) sugere a utilização da escala D-T (Delighted-Terrible; Encantado-Terrível), com sete pontos, para avaliação de vida, adaptando-a para o estudo da satisfação do consumidor. O autor mostra que essa escala possui maior validade que o caso simples da escala bipolar "satisfeito e não satisfeito". Apesar das vantagens apresentadas, o autor apenas testou e utilizou essa escala com um único item, o que não indica, necessariamente, que ela tenha desempenho superior também para escalas multi-itens.

Evrard (1993) afirma que a medição das expectativas a posteriori do consumo reforça a correlação dos construtos estudados, envolvendo uma parte de racionalização. Outras afirmações referem-se à adequação dos estudos longitudinais aos tempos necessários para a tomada de decisões, incluindo o monitoramento das soluções às reclamações (TAX; BROWN; CHANDRASHEKARAN,1998).

Möwen e Minor (1998) definem SC como uma atitude geral e como um julgamento de avaliação pós-compra resultante de uma compra específica. Esse conceito, conjuntamente com a abordagem de Oliver $(1980,1981)$ e Tse e Wilton (1988), de utilizar medições subjetivas com escalas de medidas abordando os atributos referentes ao produto ou ao serviço consumido, são essenciais na realização do presente estudo que se propõe avaliar a satisfação dos clientes.

Avaliar a satisfação do cliente se tornou tão importante para as economias dos países, que os norte-americanos estabeleceram o seu próprio índice denominado de ACSI - American Customer Sactisfaction Index, um indicador econômico que mede a satisfação dos consumidores em diversas áreas econômicas dos EUA. O modelo foi concebido por Claes Fornell, que o implementou originalmente na Suécia em 1989 com a denominação SCSB - Swedisch Customer Sactisfaction 
Barometer. Nos Estados Unidos iniciou em 1994, alocado ao centro de pesquisa da universidade de Michigan.

Segundo Fornell et al. (1996), o modelo ACSI trata a "satisfação global do cliente" como o construto central. O modelo supõe que um aumento da satisfação global do cliente deva reduzir a incidência de reclamações e aumentar a lealdade do cliente. A lealdade está ligada à probabilidade de recompra pelo cliente, além de considerar a tolerância ao preço como um fator componente.

A satisfação desencadeia uma série de avaliações que podem orientar as escolhas do consumidor. Milan e Trez (2005) afirmam que pessoas satisfeitas tendem a valorizar os atributos de um produto/serviço e a manter a estrutura de recompra sobre ela, o valor percebido pelo cliente, conforme Flint et al. (2011), é um forte condutor de satisfação e lealdade, com satisfação agindo como um mediador para a lealdade, sendo esta a disposição de um cliente para continuar a prestigiar uma empresa no longo prazo, comprar e utilizar seus bens e serviços repetidamente e, de preferência, com exclusividade, recomendando seus produtos e serviços a amigos e colegas (LOVELOCK; WRIGHT, 2001; LOVELOCK; WIRTZ, 2006; LOVELOCK; WIRTZ; HEMZO, 2011).

Para Chitty et al. (2007), o nível de satisfação ou insatisfação reflete nas intenções de recompra. Ele também pode resultar de uma reação cognitiva e afetiva a um incidente de serviço, ou uma relação de serviço em longo prazo. Estas dimensões cognitiva e afetiva, segundo Martins et al. (2011), têm sido reconhecidas na literatura como relevantes para explicar a satisfação do turista em relação a uma experiência de consumo.

De acordo com Santos (2013), satisfazer os turistas pode ser considerado um objetivo intermediário para o aumento da demanda futura na medida em que maiores níveis de satisfação implicam mais propaganda boca a boca e maior fidelidade do turista. Na visão de Sharma (2014), a satisfação do consumidor ajuda na construção de relacionamento de longo prazo. 


\section{AÇÕES DE MERCADO PARA FIDELIZAÇÃO}

Segundo Bateson e Hoffman (2010), existem vários novos programas com a finalidade de incrementar a lealdade do cliente e a sua fidelização. Entre eles: marketing de frequência, marketing de relações, post marketing, garantias do serviço e administração das deserções. O marketing de frequência combina a recopilação de dados, a comunicação, o reconhecimento do cliente e os prêmios para estabelecer relações duradouras. Em definitivo é uma forma de aumentar a produtividade dos clientes atuais (BARLOW, 1990).

O Marketing de Relações salienta a importância de manter os clientes assim como o foco na qualidade (CHRISTOPHER et al., 2002). O cliente no marketing de relações é considerado em seu sentido amplo, em que se consideram todos os grupos que participam, no desenvolvimento do processo de entrega do produto ou do serviço aos mercados. O foco do post marketing é a fidelização dos clientes, utilizando técnicas de base de dados, medição da satisfação, programas formais de comunicação e desenvolvimento de uma cultura organizacional, a fim de manter um relacionamento após a venda inicial (VAVRA, 1992). As garantias do serviço diminuem o risco percebido dos clientes porque superam suas preocupações por obter um maior valor (HART et al., 1992). A administração das deserções é um processo sistemático para manter os clientes e consiste no monitoramento dos motivos das deserções e na melhora contínua do sistema de prestação do serviço (RECHHELD; SASSER, 1990).

Para os clientes, os cartões de fidelidade emitidos pelas empresas oferecem vários tipos de benefícios, como: produtos gratuitos para membros, pontos em cartão que podem ser acumulados e trocados por outros bônus, bem como a possibilidade de elegibilidade para concursos e outras recompensas (ALLAWAY et al., 2006). Enquanto Hoffman e Bateson (2002) sistematizam as ações para a fidelização em eixos que as organizam em torno de programas, Lehu (1999) explicita as técnicas para a perpetuação da relação da empresa com seus clientes. As técnicas propostas pelo autor reúnem ações como patrocínio, newsletter, carta de informação, clube de clientes, cupons eletrônicos, cross-selling, lista na internet, merchandising, número de telefone gratuito, presentes, serviço de atendimento ao cliente, site da internet e cartão fidelidade (Tabela 1). 
Tabela 1 - Ações de marketing de fidelização

\begin{tabular}{|c|c|}
\hline $\begin{array}{l}\text { Ações de Marketing de } \\
\text { Fidelização }\end{array}$ & Definição \\
\hline Trade marketing & $\begin{array}{l}\text { Agrupa as ações que permitam maximizar as relações entre o } \\
\text { produtor e os seus distribuidores. }\end{array}$ \\
\hline ECR & $\begin{array}{l}\text { O "Efficient Consumer Response" trata de um intercâmbio de } \\
\text { informações entre o produtor e os seus distribuidores. }\end{array}$ \\
\hline Tecnologias push & $\begin{array}{l}\text { As ferramentas telemáticas permitem ao consumidor receber } \\
\text { automaticamente a informação que procura, segundo os critérios } \\
\text { escolhidos. }\end{array}$ \\
\hline Serviço pós-vendas & $\begin{array}{l}\text { Compõe-se de um conjunto de ações que uma organização } \\
\text { desenvolve para seus clientes após a venda do produto. }\end{array}$ \\
\hline Patrocínio & $\begin{array}{l}\text { A organização patrocina eventos que são de interesse de seus } \\
\text { clientes. }\end{array}$ \\
\hline Newsletter & A organização envia a seus clientes uma revista própria. \\
\hline Carta de informação & A organização emite regularmente informações a seus clientes. \\
\hline Clube de clientes & $\begin{array}{l}\text { A organização desenvolve um clube em que seus clientes podem } \\
\text { associar-se com a finalidade de obter benefícios. }\end{array}$ \\
\hline Cupom eletrônico & $\begin{array}{l}\text { O consumidor é identificado mediante a análise de sua compra e } \\
\text { gera-se um cupom de redução personalizado. }\end{array}$ \\
\hline Cross-selling & Consiste em uma venda associada. \\
\hline Lista na internet & $\begin{array}{l}\text { O consumidor subscreve-se a uma lista que lhe envia informação a } \\
\text { seu e-mail. }\end{array}$ \\
\hline Merchandising & $\begin{array}{l}\text { São técnicas comerciais que permitem determinar a localização e a } \\
\text { disposição adequada dos produtos nos pontos de vendas. }\end{array}$ \\
\hline Número de telefone gratuito & $\begin{array}{l}\text { O consumidor pode entrar em contato com um serviço de } \\
\text { informação da organização. }\end{array}$ \\
\hline Presentes & $\begin{array}{l}\text { O consumidor beneficia-se de uma vantagem materializada na } \\
\text { recepção de um presente. }\end{array}$ \\
\hline Serviço de atendimento ao cliente & $\begin{array}{l}\text { A organização desenvolve um serviço cujos clientes podem expor } \\
\text { seus comentários, observações e críticas. }\end{array}$ \\
\hline Site da internet & $\begin{array}{l}\text { Endereço informático cuja organização e o consumidor podem } \\
\text { manter um contato mais ou menos interativo. }\end{array}$ \\
\hline Cartão fidelidade & $\begin{array}{l}\text { O consumidor recebe um cartão que lhe permite obter certos } \\
\text { benefícios. }\end{array}$ \\
\hline Apadrinhamento & $\begin{array}{l}\text { A empresa incita a seus clientes a converter-se em prospectores de } \\
\text { novos clientes. }\end{array}$ \\
\hline Redes Sociais (Facebook) & $\begin{array}{l}\text { Possibilita divulgar e redirecionar potenciais clientes para o web site } \\
\text { da empresa. }\end{array}$ \\
\hline Amostras & Permite ao cliente o consumo sem custos. \\
\hline Ações baseadas na "quantidade" & Trata-se de oferecer maior quantidade pelo mesmo preço. \\
\hline Cupom desconto & $\begin{array}{l}\text { A organização se compromete a reduzir, direta ou indiretamente, o } \\
\text { preço ao apresentar o cupom. }\end{array}$ \\
\hline Reembolsos & $\begin{array}{l}\text { Assegura-se ao cliente um benefício extra ao final de um período de } \\
\text { tempo de utilização do serviço. }\end{array}$ \\
\hline Prêmios & $\begin{array}{l}\text { Consiste em dar um benefício extra a certo número de clientes, } \\
\text { criando a expectativa entre todos aqueles que participaram e } \\
\text { poderiam ser favorecidos. }\end{array}$ \\
\hline
\end{tabular}

Fonte: Adaptado de Lehu (1999). 
Finalmente, o emprego adequado de cada ação de marketing tende a aumentar a lealdade do cliente, para tanto, é fundamental ainda considerar que existem três tipos de marketing na área de serviços no turismo: o marketing externo, o marketing interno e o marketing interativo. Segundo Kotler (2015), o marketing externo é aquele realizado da empresa para o cliente. É o marketing mais tradicional, que procura atrair o cliente à empresa prestadora de serviços. O marketing interno é aquele realizado pela empresa com seu funcionário, motivando-o a realizar da melhor forma possível o seu trabalho, de modo a satisfazer os anseios dos clientes da empresa. O marketing interativo é aquele que focaliza a interação entre o cliente e o provedor do serviço.

O marketing interativo pode ser dividido em dois tipos: Tipo 1 - aquele que tenta converter o cliente potencial em cliente efetivo. Tipo 2 - aquele que desenvolve uma relação com o cliente. O marketing interativo do tipo 2 é aquele que procura a fidelização do cliente. Ações isoladas de marketing que desconsideram o marketing interativo do tipo 2 tendem a resultados inferiores.

\section{ASPECTOS METODOLÓGICOS}

O método de análise estratégica da satisfação do consumidor adotado neste estudo está baseado na proposta de análise estratégica realizada por Mello Moyano (1999). As fases do estudo são as seguintes: (1) identificação das dimensões da qualidade; (2) avaliação do nível de serviço recebido e (3) análise estratégica.

Na primeira etapa, o instrumento utilizado na identificação das dimensões da qualidade foi o do Incidente Crítico (FLANAGAN, 1954), no qual o respondente, o turista, todos aqueles com experiência de assistir ao evento, são convidados a indicar exemplos positivos e negativos da Oktoberfest de Santa Cruz do Sul (Figura 1). Nessa etapa qualitativa, o questionário foi aplicado a 20 respondentes. Foram identificadas 78 micro dimensões. Após a análise feita por três juízes, decidiu-se selecionar 23 micro dimensões da qualidade que os turistas utilizam para avaliar o evento turístico, utilizadas na etapa seguinte. A análise efetuada pelos juízes foi realizada de acordo com as etapas descritas por Hayes (2008): 
(a) classificação das micro dimensões (positivas ou negativas) por critério de repetição ou semelhança; (b) seleção ou desenvolvimento de uma dimensão que descreva os conteúdos das micro dimensões identificadas nas respostas dos entrevistados.

Para a segunda etapa, foi construído um questionário a partir das 23 dimensões e aplicado a 488 turistas, sendo a amostragem por conveniência do entrevistador. Os resultados finais obtidos com aplicação do questionário foram tabulados e analisados mediante estatística descritiva.

Figura 1 - Questionário de incidentes críticos

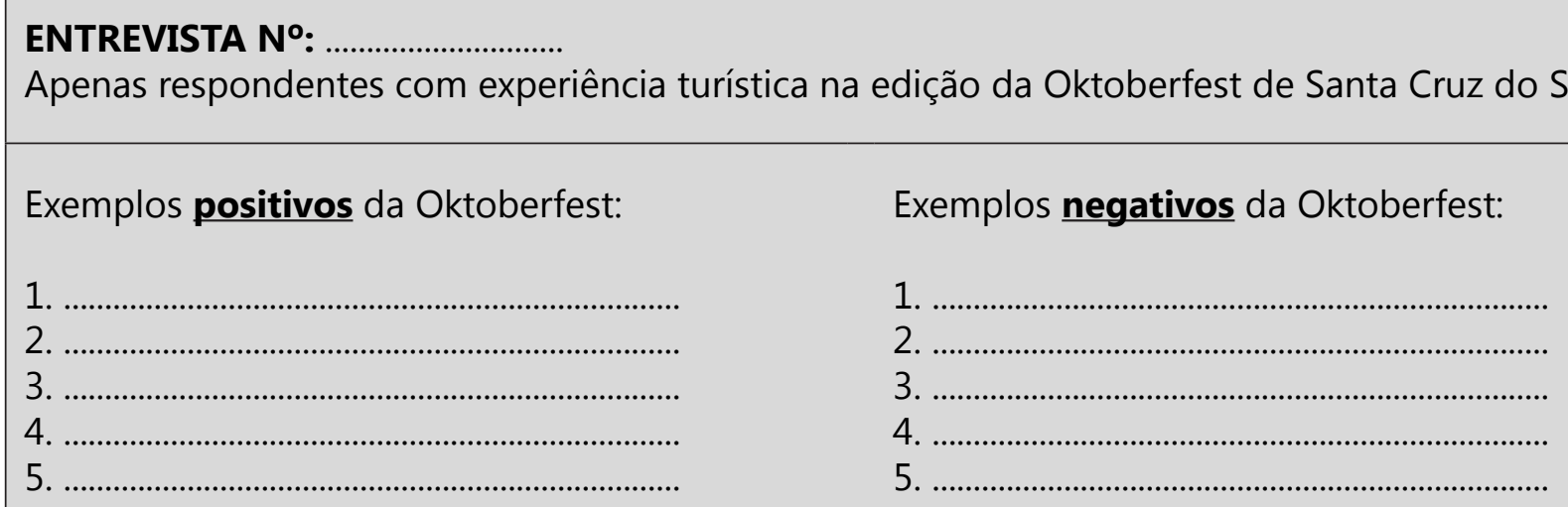

Fonte: Elaborado pelos autores.

Na terceira etapa, a análise estratégica foi desenvolvida mediante a adaptação da Matriz de Posição Competitiva (MELLO MOYANO, 1999; MELLO MOYANO; LENGLER, 2011). Uma adaptação foi necessária, já que Mello Moyano (1999) utilizou um projeto experimental com medidas "antes - depois", e no presente estudo optou-se por uma abordagem descritiva.

A matriz é composta por três fontes:

a) Posição competitiva dos entrevistados: os entrevistados foram classificados segundo as respostas em relação à variável Satisfação Global e utilizando os critérios expostos na Tabela 2;

b) Posição competitiva das dimensões avaliadas: as dimensões foram classificadas segundo a média de cada uma delas e utilizando os mesmos critérios supracitados. 
c) Estratégias de fidelização para a Oktoberfest de Santa Cruz: a partir da posição competitiva das dimensões, estabeleceram-se as estratégias de fidelização mais apropriadas para cada situação. A hierarquização da operacionalização de tais estratégias é dada pelos objetivos da gerência e o percentual dos turistas que se encontra em cada posição.

A avaliação das dimensões do serviço e dos entrevistados foi classificada em quatro categorias, segundo o escore obtido nas escalas de cinco pontos utilizadas (Tabela 2). As categorias foram denominadas e o critério utilizado para sua operacionalização são os seguintes:

a) Crise: termo que salienta a probabilidade de que os turistas que se encontram nessa situação possuem uma alta probabilidade de que não voltem ao evento e que as variáveis que se encontram nessa posição merecem uma análise exaustiva com a finalidade de uma rápida melhora. Na posição competitiva de crise, consideram-se os turistas que obtiveram um escore entre 1 e 2 na variável de Satisfação Global, já que eles refletem um alto grau de insatisfação e o mesmo critério foi considerado para as dimensões do serviço, baseado na média de cada variável;

b) Desvantagem Competitiva: considera os resultados que, sendo negativos, não chegam a uma posição extrema. Nesta posição foram considerados os escores de 2,1 até 3,49;

c) Vantagem Competitiva: estão aqueles turistas e variáveis que apresentam certo grau de satisfação. Os escores considerados foram 3,5 até 4,49;

d) A Lealdade do Cliente: considera os turistas que na variável Satisfação Global obtiveram um escore igual ou superior a 4,5 em uma escala de 5 pontos, refletindo em um resultado com alto grau de satisfação e uma alta probabilidade de que volte ao evento. As dimensões do evento foram classificadas segundo as respectivas médias. 
Tabela 2 - Critérios de pontuação para posição competitiva

\begin{tabular}{lll}
\hline Posição Competitiva & Critério de Pontuação (Escala 5 Pontos) & Estado \\
\hline 1.- Crise (C) & Até 2,00 Pontos & Insatisfação \\
2.- Desvantagem Competitiva (DC) & De 2,10 até 3,49 Pontos & \\
\cline { 2 - 3 } 3.- Vantagem Competitiva (VC) & De 3,5 até 4,49 Pontos & Satisfação \\
4.- Lealdade do Cliente (LC) & De 4,5 até 5,00 Pontos & \\
\hline
\end{tabular}

Fonte: Autores.

A partir da identificação da Posição Competitiva do evento turístico, a administração da organização do evento poderá estabelecer racionalmente um plano de ações estratégicas de fidelização para intensificar e aumentar a fidelização dos turistas em eventos futuros. As posições de crise e desvantagem competitiva tendem a promover um estado de insatisfação. Já as posições de vantagem competitiva e lealdade tendem a promover um estado de satisfação dos clientes.

\section{RESULTADOS E ANÁLISES DA PESQUISA}

A amostra do tipo não probabilística, selecionada pela conveniência do pesquisador, mas considerando o sexo e a idade, foi composta por 499 entrevistados, todos eles participantes na Oktoberfest 2011 de Santa Cruz do Sul. Desses questionários, foram rejeitados 11, principalmente por não possuírem dados de identificação e por não estarem completadas as perguntas relacionadas à satisfação. Finalmente, foram aceitos 488 questionários. As entrevistas foram realizadas em locais de estudo ou de trabalho.

A composição da amostra foi a seguinte:Considerando o sexo do entrevistado, $50 \%$ pertencem ao sexo masculino e $50 \%$ ao feminino. Segundo a escolaridade do entrevistado, $63 \%$ possuem algum grau de formação universitária e 37\% não possuem. Considerando a idade dos entrevistados, 56\% possuem de 18 a 30 anos; 44\%, de 31 a 60 anos. Do total de turistas entrevistados, 62\% moram em Santa Cruz; 23\% no Vale do Rio Pardo, 13\% em outras cidades do Rio Grande do Sul e $2 \%$ em outras cidades do Brasil (Tabela 3). 
Tabela 3: Distribuição por local de residência do entrevistado $(\%)$

\begin{tabular}{l|l}
\hline Residência & Percentual \\
Santa Cruz do Sul & 62 \\
No Vale do Rio Pardo & 23 \\
Outra cidade no RS & 13 \\
Outra cidade no Brasil & 02 \\
No exterior & 00 \\
Total Relativo (\%) & 100 \\
Total Absoluto (n) & 488 \\
\hline
\end{tabular}

Fonte: Autores da pesquisa.

Na Tabela 4 se expõem os seguintes dados:

- Na Coluna A estão as 23 micro dimensões e a Satisfação Global - variável de segunda ordem que representa a média geral das outras 23;

- Na Coluna B estão as escalas utilizadas na avaliação;

- Na Coluna C encontra-se a média de cada micro dimensão;

- Na Coluna D está a posição competitiva de cada dimensão com base nos critérios citados na metodologia do estudo (Tabela 2).

Os resultados salientam que 4 das variáveis possuem médias superiores a 3,5, sendo classificadas com um estado de Satisfação e com uma posição de Vantagem Competitiva. As 19 seguintes obtiveram médias inferiores a 3,5, sendo classificadas com estado de Insatisfação e com posição de Desvantagem Competitiva.

Tabela 4 - Posição competitiva das dimensões avaliadas 
Dor: 10.14210/rtva.v17n2.p387-413

3 - Com relação à agilidade

4 - Com relação à presteza

5 - Com relação a ser agradável

6 - Com relação ao senso de humor

7 - Com relação ao asseio

8 - Preço da festa por si só

9 - Preço da festa considerando benefícios

10 - Preço da festa considerando o atendimento

11 - Pensando na qualidade dos serviços, em geral, você diria que está

12 - Utilizando esta escala, qual é a chance de você trocar por outra festa semelhante
1 - Muito pior que o esperado e 5 - Muito melhor que o esperado

1- Muito pior que o esperado e 5 - Muito melhor que o esperado

Desvantagem

Competitiva

1 - Muito pior que o esperado e 5 - Muito melhor que o esperado

Desvantagem

Competitiva

1 - Muito pior que o esperado e 5 - Muito melhor que o esperado

1 - Muito pior que o esperado e 5 - Muito melhor que o esperado

3,40 Desvantagem Competitiva

1 - Muito caro e 5 -

Muito barato

1 - Muito caro e 5 -

Muito barato

1 - Muito caro e 5 -

Muito barato

3,43

Desvantagem

Competitiva

1 - Muito longe do ideal

e 5 - Muito perto do ideal

Desvantagem

Competitiva

1 - Com certeza trocaria

e 5 - Com certeza não $\quad 2,96$ trocaria

2,24 Desvantagem

Competitiva

2,34 Desvantagem

Competitiva

2,29

Desvantagem

Competitiva

3,37

Desvantagem

Competitiva

Desvantagem

Competitiva

1 - Com certeza trocaria

e 5 - Com certeza não $\quad 2,66$

trocaria

Desvantagem

Competitiva

1 - Com certeza trocaria

14 - Supondo que o atendimento ao consumidor

seja melhor em outra festa semelhante e,

e 5 - Com certeza não $\quad 2,61$

trocaria

Desvantagem

Competitiva você trocar

A Oktoberfest $2011 \ldots$

15 - É muito confiável

1 - Discordo Totalmente

e 5 - Concordo

3,05

Totalmente

Desvantagem

Competitiva

1 - Discordo Totalmente

16 - Se preocupa com os interesses dos seus clientes

e 5 - Concordo

3,11

Totalmente

Desvantagem

Competitiva

17 - É bastante competente no fornecimento dos seus produtos aos clientes

1 - Discordo Totalmente

e 5 - Concordo

3,22

Totalmente

Desvantagem

Competitiva

1 - Discordo Totalmente

18 - Dá informações verdadeiras/corretas aos seus clientes

e 5 - Concordo

3,49

Totalmente

Desvantagem

Competitiva

1 - Discordo Totalmente

19 - É a melhor festa do chope

e 5 -Concordo

3,37

Totalmente

Desvantagem

Competitiva 


\begin{tabular}{|c|c|c|c|}
\hline $\begin{array}{l}20 \text { - A gastronomia típica alemã é evidenciada } \\
\text { na festa }\end{array}$ & $\begin{array}{l}1 \text { - Discordo Totalmente } \\
\text { e } 5 \text {-Concordo } \\
\text { Totalmente }\end{array}$ & 3,63 & $\begin{array}{l}\text { Vantagem } \\
\text { Competitiva }\end{array}$ \\
\hline $\begin{array}{l}21 \text { - A diversidade e o interesse dos shows } \\
\text { agrada o público em geral }\end{array}$ & $\begin{array}{l}1 \text { - Discordo Totalmente } \\
\text { e } 5 \text {-Concordo } \\
\text { Totalmente }\end{array}$ & 3,76 & $\begin{array}{l}\text { Vantagem } \\
\text { Competitiva }\end{array}$ \\
\hline $\begin{array}{l}22 \text { - Oferece um ambiente limpo em todo seu } \\
\text { complexo }\end{array}$ & $\begin{array}{l}1 \text { - Discordo Totalmente } \\
\text { e } 5 \text {-Concordo } \\
\text { Totalmente }\end{array}$ & 3,23 & $\begin{array}{l}\text { Desvantagem } \\
\text { Competitiva }\end{array}$ \\
\hline 23 - A segurança no parque é satisfatória & $\begin{array}{l}1 \text { - Discordo Totalmente } \\
\text { e } 5 \text { - Concordo } \\
\text { Totalmente }\end{array}$ & 3,57 & $\begin{array}{l}\text { Vantagem } \\
\text { Competitiva }\end{array}$ \\
\hline 24 - Satisfação Global (Média gera & $\begin{array}{l}1 \text { - Muito insatisfeito e } \\
5 \text { - Muito satisfeito }\end{array}$ & 3,16 & $\begin{array}{l}\text { Desvantagem } \\
\text { Competitiva }\end{array}$ \\
\hline
\end{tabular}

Fonte: Autores da pesquisa.

Os entrevistados foram classificados, segundo as respostas em relação à variável Satisfação Global (variável de segunda ordem, desenvolvida a partir da média das respostas das 23 variáveis medidas).

O resultado obtido foi: $22 \%$ dos entrevistados situam-se na posição de vantagem competitiva, sendo que $76 \%$ em desvantagem competitiva e $2 \%$ na situação chamada de crise. Não houve respondentes na situação de lealdade (Tabela 5).

Enquanto a Tabela 4 busca categorizar a Posição Competitiva das Dimensões Avaliadas, a Tabela 5 busca categorizar a Posição Competitiva dos Entrevistados.

Tabela 5 - Posição competitiva dos entrevistados

\begin{tabular}{lll}
\hline Posição competitiva dos entrevistados & Casos & Percentual \\
\hline Lealdade & 0 & $0 \%$ \\
Vantagem Competitiva & 107 & $22 \%$ \\
Desvantagem Competitiva & 371 & $76 \%$ \\
Crise & 10 & $2 \%$ \\
Total & 488 & $100 \%$ \\
\hline
\end{tabular}

Fonte: Autores da pesquisa. 
Identificada a Posição Competitiva das dimensões (Tabela 4 - Coluna D) e dos entrevistados (Tabela 5), segue-se para Análise Estratégica, mediante a elaboração de uma Matriz Estratégica que permitirá adotarações mercadológicas concretas para o próximo evento turístico.

A análise estratégica foi desenvolvida a partir de uma Matriz de Estratégias de Fidelização (Tabela 6) que leva em consideração a Posição Competitiva das Dimensões Avaliadas (Tabela 4) e a Posição Competitiva dos Entrevistados (Tabela 5). Com base nas posições competitivas descritas na seção anterior, desenvolveram-se quatro conjuntos de estratégias de fidelização, segundo as posições competitivas. A cada uma das posições competitivas Ihe foi atribuído um conjunto de estratégias de fidelização de acordo com suas particularidades e exigências em termos de aplicação da estratégia de marketing. A criticidade de cada condição competitiva condicionou a atribuição das estratégias de fidelização. Tais estratégias foram categorizadas em quatro grupos, que são os seguintes: Vendas, Comunicação sem Interação, Benefícios e Comunicação com Interação.

As estratégias denominadas de Vendas (V) possuem como finalidade o estímulo à recompra. As de Comunicação sem Interação (CSI) dedicam-se a manter os consumidores informados sobre as novidades da empresa e seus produtos e dessa forma estimular as vendas de forma indireta. Os Benefícios (B) procuram dar ao cliente um prêmio pelo histórico de relação com a empresa. $A$ Comunicação com Interação (CCI) tem por finalidade estabelecer um canal de comunicação direto com o consumidor para uma correta utilização do produto ou do serviço (MELLO MOYANO; LENGLER, 2012) (Tabela 6).

Tabela 6 - Estratégias de fidelização e ações de marketing

\begin{tabular}{|c|c|c|}
\hline $\begin{array}{l}\text { Estratégias de } \\
\text { Fidelização }\end{array}$ & Definição & Ações de Marketing de Fidelização \\
\hline Vendas (V) & $\begin{array}{l}\text { Possuem como finalidade o estímulo à } \\
\text { recompra }\end{array}$ & Patrocínio, Cross-selling e Merchandising \\
\hline $\begin{array}{l}\text { Comunicação sem } \\
\text { Interação (CSI) }\end{array}$ & $\begin{array}{l}\text { Dedicam-se a manter os consumidores } \\
\text { informados sobre as novidades da } \\
\text { empresa e seus produtos e dessa } \\
\text { forma estimular as vendas de forma } \\
\text { indireta }\end{array}$ & $\begin{array}{l}\text { Newsletter, Carta de informação, Lista na } \\
\text { internet }\end{array}$ \\
\hline Benefícios (B) & $\begin{array}{l}\text { Procuram dar ao cliente um prêmio } \\
\text { pelo histórico de relação com a } \\
\text { empresa }\end{array}$ & $\begin{array}{l}\text { Clube de clientes, Couponing eletrônico, } \\
\text { Presentes e Cartão de fidelidade }\end{array}$ \\
\hline
\end{tabular}


Comunicação com Interação (CCI)
Tem por finalidade estabelecer um canal de comunicação direto com o consumidor para uma correta utilização do produto ou serviço
Número de telefone gratuito, Facebook, Trade marketing, ECR, Tecnologias push, Número de telefone gratuito, Serviço de atendimento ao cliente, Site da internet, Atendimento ao cliente e Serviço pós-vendas

Fonte: Mello Moyano e Lengler (2012).

Conhecidas as estratégias de fidelização, realiza-se uma análise individual para cada posição competitiva. A partir de uma revisão teórica, estabelecem-se as estratégias de fidelização mais apropriadas para cada situação. A Figura 2 poderá subsediar os administradores nesse processo de planejamento.

Figura 2 - Posicionamento Estratégico versus Estratégia de Fidelização

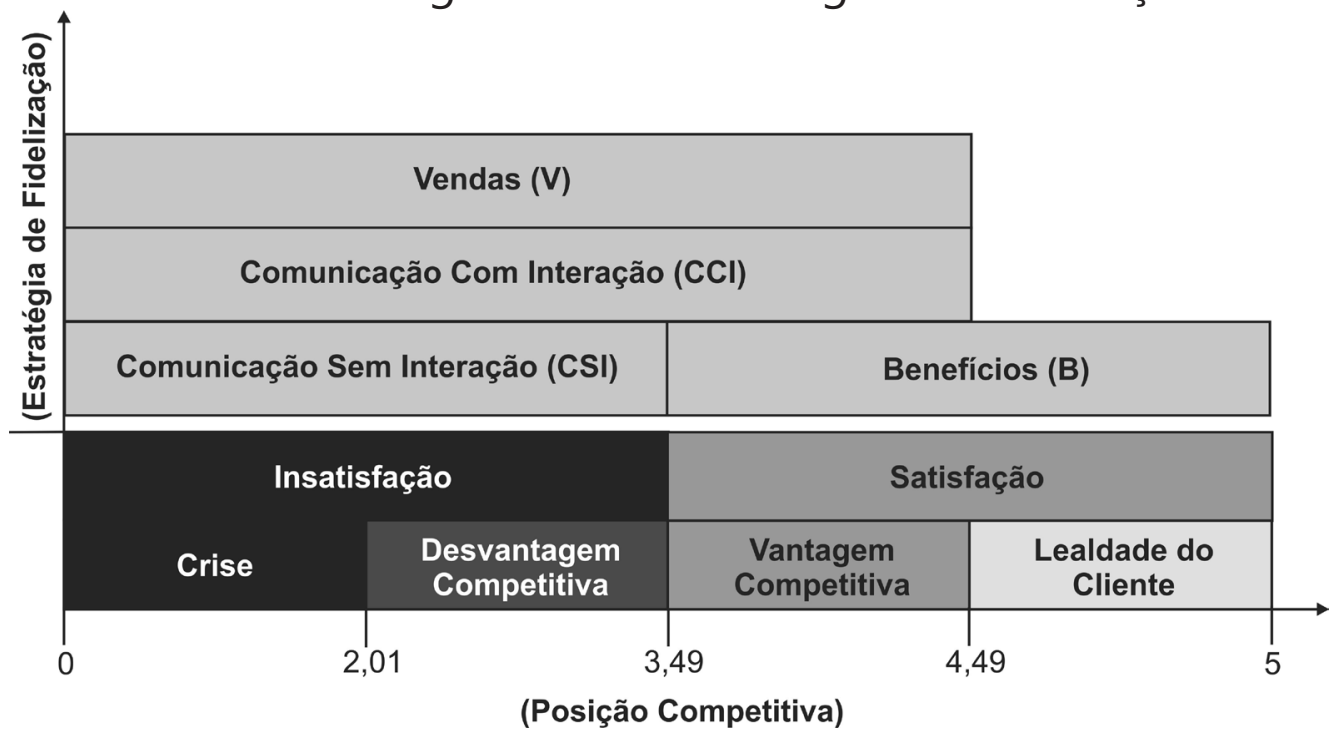

Fonte: Autores.

A Tabela 7 apresenta o encerramento do processo estratégico para fidelização a partir de uma Matriz de Estratégias.

Segundo a distribuição dos entrevistados em relação à avaliação geral do serviço recebido, o percentual que se encontra em situação de vantagem competitiva são $22 \%$, em desvantagem competitiva são $76 \%$, em situação de crise estão $2 \%$ dos casos, finalmente em situação de lealdade não se encontram entrevistados. 
Cada uma das dimensões avaliadas também recebeu um posicionamento competitivo, sendo que neste critério são avaliadas as médias gerais de cada dimensão e posteriormente agrupadas por critério de posicionamento competitivo. Observa-se que não houve nenhuma dimensão enquadrada nas posições de crise e de lealdade, embora a posição de crise tenha tido casos individuais (2\%), porém na média geral dos casos, não houve nenhuma dimensão que se enquadrasse nesse posicionamento. A posição com um maior percentual de respondentes (76\% dos casos) e dimensões avaliadas (19) foi para a posição Desvantagem Competitiva, o que significa que, de modo geral, as pessoas que avaliaram o evento turístico estão moderadamente insatisfeitas e que as dimensões em que este aspecto ficou mais nítido, na média geral, foram evidenciadas nas 19 dimensões avaliadas.

Tabela 7 - Matriz de posição competitiva e estratégias de fidelização

\begin{tabular}{|c|c|c|c|c|c|c|c|}
\hline \multirow{2}{*}{$\begin{array}{l}\text { Avaliação } \\
\text { do } \\
\text { Serviço } \\
\text { (Escala } \\
0-5 \\
\text { pontos) }\end{array}$} & \multirow{2}{*}{$\begin{array}{l}\text { Distribuição } \\
\text { dos } \\
\text { entrevistados } \\
\text { segundo a } \\
\text { Satisfação } \\
\text { Global com o } \\
\text { serviço }\end{array}$} & \multirow[b]{2}{*}{$\begin{array}{l}\text { Posição } \\
\text { Competitiva }\end{array}$} & \multirow[b]{2}{*}{ Dimensões Avaliadas } & \multicolumn{4}{|c|}{$\begin{array}{l}\text { Estratégias de } \\
\text { Fidelização }\end{array}$} \\
\hline & & & & B & V & $\mathrm{CCI}$ & CSI \\
\hline $\begin{array}{l}\text { Entre } 4,5 \\
\text { e } 5,00\end{array}$ & $0 \%$ & $\begin{array}{l}\text { Lealdade do } \\
\text { cliente }\end{array}$ & Nenhum & {$[\mathrm{X}]$} & [ & [ ] & [ ] \\
\hline $\begin{array}{l}\text { Entre } 3,50 \\
\text { e } 4,49\end{array}$ & $22 \%$ & $\begin{array}{l}\text { Vantagem } \\
\text { Competitiva }\end{array}$ & $\begin{array}{l}1 \text { - Gostaria que você avaliasse de } \\
\text { maneira geral a qualidade dos serviços; } \\
20 \text { - A gastronomia típica alemã é } \\
\text { evidenciada na festa; } \\
21 \text { - A diversidade e o interesse dos } \\
\text { shows agrada o público em geral; } \\
23 \text { - A segurança no parque é } \\
\text { satisfatória. }\end{array}$ & {$[\mathrm{X}]$} & {$[\mathrm{X}]$} & {$[\mathrm{X}]$} & [ ] \\
\hline
\end{tabular}




\begin{tabular}{|c|c|c|c|c|c|}
\hline $\begin{array}{l}\text { Entre } 2,01 \\
\text { e } 3,49\end{array}$ & $76 \%$ & $\begin{array}{l}\text { Desvantagem } \\
\text { Competitiva }\end{array}$ & $\begin{array}{l}2 \text { - Com relação ao atendimento geral, } \\
\text { qual das frases está mais de acordo com } \\
\text { sua opinião; } \\
3 \text { - Com relação à agilidade; } \\
4 \text { - Com relação a ser prestativos; } \\
5 \text { - Com relação a ser agradável; } \\
6 \text { - Com relação ao senso de humor; } \\
7 \text { - Com relação ao asseio; } \\
8 \text { - Preço da festa por si só; } \\
9 \text { - Preço da festa considerando } \\
\text { benefícios; } \\
10 \text { - Preço da festa considerando o } \\
\text { atendimento; } \\
11 \text { - Pensando na qualidade dos } \\
\text { serviços, em geral, você diria que está; } \\
12 \text { - Utilizando esta escala, qual é a } \\
\text { chance de você trocar por outra festa } \\
\text { semelhante; } \\
13 \text { - Agora, supondo que o preço de } \\
\text { outra festa semelhante seja melhor, } \\
\text { utilizando esta mesma escala, qual é a } \\
\text { chance de você trocar; } \\
14 \text { - Supondo que o atendimento ao } \\
\text { consumidor seja melhor em outra festa } \\
\text { semelhante e, utilizando esta mesma } \\
\text { escala, qual é a chance de você trocar; } \\
15 \text { - É muito confiável; } \\
16 \text { - Preocupa-se com os interesses dos } \\
\text { seus clientes; } \\
17 \text { - É bastante competente no } \\
\text { fornecimento de seus produtos aos } \\
\text { clientes; } \\
18 \text { - Dá informações verdadeiras/ } \\
\text { corretas a seus clientes; } \\
19 \text { - É a melhor festa do chopp; } \\
22 \text { - Oferece um ambiente limpo em } \\
\text { todo seu complexo. }\end{array}$ & {$\left[\begin{array}{lll}{[} & {[X]} & {[X]}\end{array}\right.$} & {$[\mathrm{X}]$} \\
\hline Até 2,00 & $2 \%$ & Crise & Nenhum & {$\left[\begin{array}{lll}{[} & {[X]} & {[X]}\end{array}\right.$} & {$[\mathrm{X}]$} \\
\hline
\end{tabular}

Fonte: Pesquisa realizada pelos autores.

Considerando os resultados das estratégias mais adequadas com a finalidade de amenizar a Desvantagem Competitiva, estão: Vendas, Comunicação sem Interação e Comunicação com Interação. A escolha das ações mais adequadas poderá ser realizada após uma análise de custo/benefício. As ações mercadologicas decorrentes para o posicionamento desvantagem competitiva são as seguintes: (a) Vendas: Patrocínio, Cross-selling e Merchandising. (b) Comunicação sem Interação: Newsletter, Carta de informação, Lista na internet. 
(c) Comunicação com Interação: Número de telefone gratuito, Atendimento ao cliente e Serviço pós-vendas. A Figura 2 ilustra sinteticamente a Matriz de Posição Competiviva versus a Estratégia de Fidelização.

Sob o ponto de vista de custos para empresa ou organizadora do evento, manter uma posição competitiva com clientes leais representa investimentos menores em estratégias com ações de marketing para manutenção e retenção do cliente.

\section{CONCLUSÕES}

Este estudo teve por objetivo propor o desenvolvimento de estratégias de marketing com base na satisfação do consumidor de serviços para eventos de turismo, especificamente da Oktoberfest 2011 de Santa Cruz do Sul/RS (Brasil), baseadas a partir de uma modificação das propostas de Mello Moyano (1999) e Mello Moyano e Lengler (2011). Os objetivos específicos propostos foram: primeiramente, gerar dimensões da qualidade que comporiam o instrumento de identificação da satisfação dos consumidores da Oktoberfest; o segundo, medir a avaliação do serviço recebido; em seguida, desenvolveu-se uma matriz de posição competitiva baseada na avaliação do evento. Por fim, atendendo ao objetivo geral deste estudo, foi desenvolvido um conjunto de estratégias de marketing para serem implementadas nos próximos eventos, com base nas posições competitivas identificadas anteriormente.

Podem-se salientar três contribuições para os profissionais pertencentes a organizações desse tipo de eventos:

A primeira é a inclusão da perspectiva do cliente para a elaboração da estratégia de marketing. Neste método, o ponto original para a proposição das estratégias de marketing são as percepções e as avaliações do consumidor (turista) que possuem um caráter orientador.

A segunda contribuição refere-se à adapatação da matriz de posição competitiva, assim como dos indicadores que são utilizados na sua formulação. A utilização da matriz permite o incremento da racionalidade no processo decissório mediante a seleção da estratégia de marketing mais adequada por parte dos gestores desse tipo de evento de turismo, já que fornece um marco de análise. 
A terceira contribuição é a alocação de um conjunto de estratégias e respectivas ações de marketing para o turismo, segundo o resultado de cada uma das dimensões de avaliação e sua posição competitiva na matriz.

Portanto, destaca-se que o estudo proporcionou uma sistematização metodológica prática para profissionais de tursimo e gestores de eventos, no intuito de facilitar a implementação de estratégias de fidelização mercadológica a partir da pespectiva do cliente em eventos turísticos.

Como limitações do trabalho, elenca-se o fato de a pesquisa ter sido realizada em um único evento da Oktoberfest de uma única cidade. Diferenças regionais podem influenciar nos resultados apresentados, mas não comprometem a sistematização metodológica da matriz estratégica.

Para estudos futuros, sugere-se a replicação da metodologia e da matriz de posição competitiva e de estratégia de fidelização para outros eventos turísticos, bem como a mensuração comparativa, sobretudo financeria/econômica, dos resultados finais, antes e após a adoção das estratégias de fidelização, proporcionadas pelo conjunto de medidas de ações mercadológicas adotadas. Provavelmente, variáveis circustânciais e externas poderão interferir nesse aspecto do estudo, como: variáveis políticas, macroeconômicas e até mesmo variáveis ambientais climáticas que se alteram, influenciando decisões turísticas entre um evento e outro, o que talvez tornasse esse tipo de comparação um tanto quanto desafiador e complexo para futuros estudos.

\section{REFERÊNCIAS}

ALLAWAY, A.; GOONER, R.; BERKOWITZ, D.; DAVIS, L. Deriving and Exploring Behavior Segments Within a Retail Loyalty Card Program. European Journal of Marketing. v. 40, n. 11, p. 1317-1339, 2006.

ANDERSON, E. W.; FORNELL, C.; LEHMANN, D. R. Customer Satisfaction, Market Share, and Profitability: Findings from Sweden. Journal of Marketing. v. 58, n. 3, p. 53-66, 1994.

BARLOW, R. Building Customer Loyalty Trough Frecuency Marketing. The Bankers Magazine. v. may/june, p. 73-76, 1990.

BLACKWELL, R. D.; MINIARD P. W.; ENGEL, J. F. Comportamento do consumidor. São Paulo: Cengage Learning, 2013. 
BLOEMER, J.; POLESZ, T. B. The Illusion of Consumer Satisfaction. Journal of Consumer Satisfaction, Dissatisfaction and Complaining Behavior. v. 2,1989.

CADOTTE, E. R.; WOODRUFF, R. B.; JENKINS, R. L. Expectations and Norms in Models of Consumer Expectations. Journal of Marketing Research. v. 24, p. 305-314, 1987

CHITTY, B.; WARD, S.; CHUA, C. An Application of the ECSI Model as a Predictor of Satisfaction and Loyalty for Backpacker Hostels. Marketing Intelligence \& Planning. v. 25, n. 6, 2007.

CHRISTOPHER, M.; PAYNE, A.; BALLANTYNE, D. Relationship Marketing: Creating Stakeholder Value. Oxford: Elsevier, 2002.

DAGGER, T. S.; DAVID, M. E. Uncovering the real effect of switching costs on the satisfactionloyalty association. European Journal of Marketing, Vol. 46 Iss 3/4 pp. 447 - 468, 2012.

DUBOIS, B. Comprendre Le Consommateur. Paris: Dalloz, 1990.

EVRARD, Y. Consumer Satisfaction as a Social Indicator. Esomar Congress Proceedings Social Change Analysis. p. 219-234, 1980.

EVRARD, Y. La Satisfaction des Consommateurs: État des Recherches. Encontro Nacional da Associação Nacional dos Programas de Pós-graduação em Administração. n. 17, Salvador, p. 59-86, 1993.

FLANAGAN, J. C. The Critical Incident Technique. Psychological Bulletin. v. 5, n. 4, p. 327358, 1954.

FLINT, D. J; BLOCKER, C. P; BOUTIN JR, P. Customer Value Anticipation, Customer Satisfaction and Loyalty: An Empirical Examination. Industrial Marketing Management. v. 40, n. 2, p. 219-230, 2011.

FORNELL, C. A National Customer Satisfaction Barometer: The Swedish Experience. Journal of Marketing, v. 56, jan., p. 6-21, 1992.

FORNELL, C.; JOHNSON, M. D.; ANDERSON, E. W.; CHA, J.; BRIANT, B. E. The American Customer Satisfaction Index: Nature, Purpose, and Findings. Journal of Marketing. v. 60, n. 4, p. 7-18, 1996.

GIESE, J. L.; COTE, J. A. Defining Consumer Satisfaction. Academy of Marketing Science Review. v. 2000, n. 1, 2002.

GOSLING, M.; SOUZA, B.B.P.; ARAÚJO, G.C.D. Dimensões da Qualidade de Serviços, Satisfação e Lealdade: Um Modelo Teórico. XXVI ENEGEP - Fortaleza, CE, Brasil, 9 a 11 de Outubro de 2006. 
GREWAL, D. Product Quality Expectations: Towards an Understanding of Their Antecedents and Consequences. Journal of Business and Psychology. v. 9, spring, p. 225-240, 1995.

HART, C. W. L.; SCHLESINGER, L. A.; MAHER, D. Guarantees Come to Professional Service Firms. Sloan Management Review. v. 33, n. 3, p. 19-29, 1992.

HAYES, B. E. Measuring customer satisfaction and loyalty: survey design, use, and statistical analysis methods. 3. ed. Milwaukee: American Society for Quality. 2008.

BATESON, J.; HOFFMAN, D. Services Marketing. 4. ed. Cengage Learning, 2010.

HOWARD, J.; SHETH, J. A. Theory of Buyer Behavior. New York: Wiley, 1969.

HUNT, K. H. Conceptualization and Measurement of Consumer Satisfaction and Dissatisfaction. Boston: Marketing Science Institute, 1977.

KOTLER, P. Fundamentos de Marketing. México: PHB, 2013.

KOTLER, P. Princípios de marketing. 15. ed. São Paulo: Pearson Education do Brasil, 2015.

LABARBERA, P. A.; MAZURSKY, D. A Longitudinal Assessment of Consumer Satisfaction/ Dissatisfaction: The Dynamic Aspect of the Cognitive Process. Journal of Marketing Research. v. 20, n. 4, p. 393-404, 1993.

LEHU, J.M. La Fidélization-Client. Paris: Éditions d'Organizations, 1999.

LOVELOCK, C.; WIRTZ, J. Marketing de Serviços: Pessoas, Tecnologia e Resultados. 5. ed. São Paulo: Pearson Prentice Hall, 2006.

LOVELOCK, C.; WIRTZ, J., HEMZO, M. Marketing de serviços: pessoas, tecnologia e estratégia. 7. ed. São Paulo: Pearson prentice Hall, 2011.

LOVELOCK, C.; WRIGHT, L. Serviços: Marketing e Gestão. São Paulo: Saraiva, 2001.

MARTINS, C. C.; MENDES, J. C.; GUERREIRO, M. M. M. Monitorização da Satisfação dos Turistas com os Safaris. Turismo em Análise. Vol. 22, n. 1, abril, 2011.

MCKERCHER, B.; MEI, W.; TSE, T. Are Short Duration Festivals Tourist Atractions? Journal of Sustainable Tourism. v.14, n. 1, p. 55-66, 2006.

MELLO MOYANO, C. Desenvolvimento de um Instrumento de Pesquisa para a Avaliação da Satisfação do Consumidor de Serviços de Turismo: Um Estudo Exploratório. 1999. 163f. Tese (Doutorado em Administração) - UFRGS, Porto Alegre, 1999. 
MELLO MOYANO, Carlos; LENGLER, J. The use of adapted ACSI satisfaction model to tourism companies to the proposition of loyalty strategies: The case of the 2011 Oktoberfest in Brazil. In: 2nd Advances in Hospitality and Tourism Marketing \& Management (AHTMM), Corfu Island, 2012.

MELLO MOYANO, Carlos; LENGLER, J. Proposta de um Modelo para o Desenvolvimento da Estratégia de Marketing de Empresas de Turismo com Base na Satisfação do Consumidor. In: VIII Seminário da Associação Nacional de Pesquisa e Pós-Graduação em Turismo, Camboriu, 2011.

MILAN, G. S.; TREZ, G. Pesquisa de Satisfação: Um Modelo para Planos de Saúde. Revista de Administração de Empresas Eletrônica. v. 4, n. 2, 2005.

MÖWEN, J. C.; MINOR, M. Consumer Behavior. Upper Saddle River: Prentice-Hall, 1998.

OKTOBERFEST. História da Oktoberfest. Disponível em: http://pt.shvoong.com/humanities/ history/1688778-oktoberfest-brasil/. Acessado em outubro de 2011.

OKTOBERFEST. Oktoberfest no Brasil. Disponível em: http://pt.wikipedia.org/wiki/ Oktoberfest. Acesso em: novembro de 2013.

OLIVER, R. A. Cognitive Model of the Antecedents and Consequences of Satisfaction Decisions. Journal of Marketing Research. v. 17, n. 4, p. 460-469, 1980.

OLIVER, R. A. Measurement and Evaluation of Satisfaction Process in Retails Settings. Journal of Retailing. v. 57, n. 3, p. 25-49, 1981.

RECHHELD, F.; SASSER, E. Zero Defections: Quality Comes to Services. Harvard Business Review. September/October, 1990.

RIBEIRO, A. H. P.; HANNA, A. K.F.A.; MONTEIRO, P.R.R. O Valor Gerado na Experiência de Consumo e Lealdade: A Operacionalização dos Construtos e suas Relações. XXX EnAnpad - Salvador, BA, Brasil, 23 a 27 de Setembro de 2006.

SANTOS, G. E. O Que Determina a Satisfação dos Turistas Internacionais no Brasil? Turismo em Análise. Vol. 24, n. 2, agosto, 2013.

SHAN, S.; LI, C.; YAO, W.; SHI, J.; REN, J. An empirical study on critical factors affecting employee satisfaction. Systems Research and Behavioral Science. v. 31, 2014.

SHARMA, R. B. Customers satisfaction in telecom sector in saudi arabia: An empirical investigation. European Scientific Journal, edition vol.10, No.13, May 2014.

TAX, S. S.; BROWN, S. W.; CHANDRASHEKARAN, M. Customer Evaluations of Service 
ISSN: 1983-7151

Complaint Experiences: Implications for Relationship Marketing. Journal of Marketing. v. 62 n. 2, p. 60-76, 1998.

TSE, D. K.; WILTON, P. C. Models of Consumer Satisfaction: An Extension. Journal of Marketing Research. v. 25, n. 2, p. 204-212, 1988.

VAVRA, T. Aftermarketing. Homewood: Irwin, 1992.

VOSS, G. B.; PARASURAMAN, A.; GREWAL, D. The Roles of Price, Performance, and Expectations in Determining Satisfaction in Service Exchanges. Journal of Marketing. v. 62 n. 4, p. 46-59, 1998.

WATANABE, E. A M. Atributos de Imagem da Loja e a Satisfação de Clientes com os Supermercados de Campo Grande/MS. 2010.97f. Dissertação (Mestradoem Administração) UFMS, Campo Grande, 2010.

WESTBROOK, P. A. Sources of Consumer Satisfaction with Retail Outlets. Journal of Retailing. v. 5, aug, 1980 . 